\title{
A PRESERVAÇÃO DE BENS CULTURAIS NO BRASIL - RESPEITO E CONSCIENTIZAÇÃO SOCIAL
}

\author{
Ana Catarina P. T. Ramos *
}

RESUMO: Este artigo trata de ações, diretrizes e leis estabelecidas no Brasil visando à preservação dos seus bens culturais. Traça uma síntese sobre o início dessa proteção, remontando à chegada dos portugueses, que emitiram legislação voltada à proteção do patrimônio natural do Brasil, discorre sobre as Cartas Patrimoniais que buscaram lançar diretrizes para a preservação dos bens históricos e culturais em escala global, chegando até os dias de hoje. Nesse longo percurso percebe-se o quanto ainda precisa-se empenhar na defesa de nossas tradições culturais. Nesses mais de cinco séculos foi elaborada uma legislação voltada para a proteção dos bens culturais, mas, mesmo assim muito do patrimônio não foi preservado. 0 respeito e a conscientização social da necessidade de defesa do patrimônio cultural estão longe de ser uma realidade que promova a sua proteção contra o interesse dos não comprometidos e não identificados com a história. É o que se ver, por exemplo, quando em uma clara ação de desconstrução de um lento e difícil processo de conscientização, acontece a luta pela aprovação do Decreto Legislativo $n^{\circ} 540$, de 10 de outubro de 2016, medida que põe abaixo conquistas e avanços, com o objetivo de sustar um importante mecanismo de proteção ao patrimônio arqueológico, a Instrução Normativa do IPHAN nº 001, de 25 de março de 2015. Palavras-chave: Preservação; Bens culturais; Cartas Patrimoniais.

ABSTRACT: This article discusses actions, guidelines and laws established in Brazil, aiming at the preservation of their cultural heritage. Traces an overview of the beginning of this protection, dating back to the arrival of the Portuguese, who have issued legislation aimed at protecting the natural heritage of Brazil, talks about Heritage letters that sought release guidelines for the preservation of historical and cultural goods on a global scale, right down to the present day. In this long journey one realizes how much it still needs to work on defending cultural traditions. In these more than five centuries was an elaborate legislation geared towards the protection of cultural property, but even so much of our heritage has not been preserved. Respect and social awareness of the need to defend our cultural heritage is far from a reality that promotes your protection against the interest of non-committed and not identified with our history. Is what we see, for example, when a clear action of deconstruction of a slow and difficult process of conscientization, happens to struggle for approval of Legislative Decree 540 of 10 October 2016, as put down achievements and advances, in order to stop an important mechanism of protection of the archaeological heritage, IPHAN normative instruction no ${ }^{\circ} 001$, 25 March 2015. 
A questão da preservação do patrimônio natural já vem sendo pensada no Brasil desde os primeiros anos da colonização, mas foi apenas no século XX que surgiram ações que demonstraram uma maior preocupação com os bens culturais brasileiros de uma maneira geral. No século XX, desde as primeiras décadas, começou a se esboçar a preocupação e os cuidados para com o registro cultural, histórico e natural. Como resposta a essa atitude, surgem e são implementadas leis, decretos e criam-se órgãos representativos, responsáveis por ações de salvaguarda do corpo patrimonial ${ }^{1}$.

No entanto, apesar dos esforços, o que ocorreu nas décadas seguintes foi apenas um lento avanço nesse campo e acontece, na maioria das cidades brasileiras, uma considerável destruição de boa parte do patrimônio nacional. Naquela época e posteriormente foram criadas entidades que tomaram para si a incumbência de tratar da conservação e preservação desse patrimônio. Foram criados instrumentos de financiamento dentro de uma política cultural nacional, onde foram alocados recursos públicos para financiar programas, projetos e instituições. Esse financiamento ocorria, muitas vezes, de forma limitada o que privilegiava setores determinados, numa ausência de abrangência nacional.

De uma maneira geral, as políticas públicas voltadas à preservação provocaram alguns avanços, mas na verdade, não conseguiram efetivar uma atitude consciente e contínua de preservação e respeito ao patrimônio. O desafio de preservar pede a participação da sociedade como um todo. Essa vivência tem mostrado que apenas quando acontece uma efetiva participação da sociedade junto às entidades e da classe política, solicitando e acompanhando a salvaguarda de seu patrimônio e o estabelecimento de políticas públicas eficazes a ideia de preservação funciona.

As experiências em outras nações têm demonstrado que a preservação e proteção dos bens patrimoniais só são efetivadas quando o agente dessa proteção é a própria população. Quanto maior a participação da sociedade maior será o debate público em torno das atitudes a serem tomadas no processo de preservação gerando uma cadeia de co-responsabilidades entre todos envolvidos. Os que detêm o poder de formular e promulgar as leis, decretos e emendas fazem parte dessa cadeia e deles dependemos para efetivar uma legislação protetora de nossa cultura. Esse artigo trata do desenvolvimento histórico das ações, recomendações e leis estabelecidas, num contexto local e mundial que contribuíram na formação de uma legislação para a proteção do patrimônio cultural brasileiro.

\section{Antecedentes}

De certa maneira pode-se afirmar que o início da proteção patrimonial no Brasil se dá quando da chegada dos portugueses. A ordem jurídica Portuguesa baseava-se nas Ordenções que eram também aplicadas no Brasil. Naquele tempo, vigoravam em Portugal as Ordenções

\footnotetext{
${ }^{1}$ Em 1920 foi elaborado o anteprojeto de lei de defesa do patrimônio artístico, inclusive dos bens arqueológicos. Em 3 de dezembro de 1923 foi aprovado na Câmara dos Deputados o projeto de lei que propõe a criação da inspetoria dos Monumentos Históricos. Em 16 de outubro de 1924 a mesma Câmara aprova o projeto de lei que visa proibir a saída do país de "obras de arte tradicional brasileira". Em 24 de agosto de 1928 foi criada em Pernambuco a Inspetoria Estadual de Monumentos Nacionais (RAMOS, 2006).
} 
Afonsinas, primeiro Código Legislativo europeu de $1446^{2}$, onde constavam disposições legislativas protetoras do meio ambiente. Uma preocupação compreensível diante da necessidade preemente do emprego das riquezas naturais para impulsionar a expansão ultramarina portuguesa. Se o meio ambiente se degradasse, a expansão pretendida estaria comprometida.

Durante a ocupação das terras brasileiras, foram graves os problemas pela falta de gêneros alimenícios e seus altos preços em Portugal. O Instituto das sesmarias, que já existia em Portugal desde 1375, foi apliado no Brasil como forma de organizar a apropriação fundiária. Essa medida, termina por incrementar o cultivo de um maior número de terras. Os governos das capitanias hereditárias doavam, a quem se dispusesse a cultivar, pedaços de terra devoluta ou abandonada. Parte de tudo que era cultivado em cada sesmaria destinava-se ao reino de Portugal. Vale lembrar que foi nesse período que mais se extraiu do solo brasileiro o paubrasil, uma das grandes riquezas nacionais.

As segundas ordenações, as Ordenações Manuelinas ${ }^{3}$ (1514-1603), que foram determinadas pela existência de vultoso número de leis e atos modificadores das Ordenações Afonsinas, apresentam disposições protecionistas mais detalhadas. Proibiu-se a caça de perdizes, lebres e coelhos em redes, fios ou outros meios e instrumentos capazes de causar dor e sofrimento na morte desses animais.

A coroa portuguesa zelou por emitir ordens para proteger, cada vez mais, o que hoje chamamos de meio ambiente. Todavia, podemos notar que a intenção não era preservá-lo ecologicamente equilibrado para futuras gerações mas, tão somente, para ter de onde retirar alimentos e matéria-prima, em especial, para a Monarquia. Tanto é assim que era incentivada amplamente, sem restrições a exploração dos recursos naturais como ouro, pedras preciosas e madeiras, por se constituirem exclusivo régio, sobretudo por constituirem o lastro monetário exigido pela política mercantilista adotada na Europa.

Desde o início da colonização alguns intelectuais brasileiros alertavam sobre as agressões contra o patrimônio brasileiro, principalmente o natural, apesar da pouquíssima ou nenhuma repercussão:

Frei Vicente de Salvador, em 1697: “E isso não tem só os que de lá vieram, mas ainda os que cá nasceram, que uns e outros usam da terra não como senhores, mas como usufrutários, só para a desfrutarem e a deixarem e a deixarem destruída."

Baltasar da Silva Lisboa, em 1786: “É incompreensível a imensa quantidade de lenha que inutilmente consome a feitura do açúcar pela construção das suas fornalhas, pois que para uma carrada de cana se requer outra de lenha."

\footnotetext{
${ }^{2}$ As Ordenações Afonsinas eram a atribuídas a João Mendes, Rui Fernandes, Lopo Vasques, Luis Martins e Fernão Rodrigues, foram elaboradas sob os reinados de João I, D. Duarte e Afonso V. Como o trabalho foi finalizado no reinado de Afonso V, recebeu o nome de Ordenações Afonsinas (1446) (Dias, 2002)

3 As ordenações Manuelinas (1514-1603) foram compiladas por: Rui Boto, Rui da Grá e João Cotrim, que iniciaram os trabalhos em 1501, no reinado do Dom Manuel I e terminaram, mais ou menos, em 1514 (Dias, 2002).
} 
Manuel Ferreira da Câmara Bittencourt e Sá, em 1789: "Portanto creio que interessará muito ao estado expedir não ordens meramente, porque algumas já as tem expedido, se bem sem proveito, mas ministros que vigiem e regulem o corte de madeiras indistintamente, obrigando os proprietários dos terrenos marítmos a conservar ilesas as de construção, que ocupando uma parte pequena do seu terreno não danificam por certo a sua cultura."

José Vieira Couto, em 1799: "O agricultor olha ao redor de si para duas ou mais léguas de matas, como para um nada, e ainda não as tem bem reduzido a cinzas já estende ao longe a vista para levar a destruição de outras partes. Não conserva apego nem amor ao território que cultiva, pois conhece mui bem que ele talvez não chegará a seus filhos."

Manoel Arruda da Câmara, em 1809: "Daqui se vê a necessidade de proibirse as derrubadas de matas virgens, nas que são abundosas de almécegas, como também a de vedar-se o soltarem fogos, o que se não poderá conseguir sem fulminar alguma combinação de penas contra os agressores."

José Severino Maciel da Costa, em 1821: "São raros os cultivadores que escolhem terreno, nele se fixam e procuram tirar dele, por meio do estudo e da experiência, o partido possível; os mesmos que obtêm sesmarias, enquanto há matas que derribar, fazem todos os anos roçados. Por tal método jamais a cultura se aperfeiçoará, porque o homem não emprega diligência alguma e tudo é obra da natureza, e em poucos anos o país apresentará um estado cadavérico, se nos podemos explicar assim, como já acontece em algumas capitanias."

Joaquim Nabuco, em 1888: "A influência da escravidão sobre o território e a população que vive dele foi em todos os sentidos desastrosa. (...) O caráter de sua cultura é a imprevidência e a rotina, a indiferença pela máquina, o mais completo desprezo pelos interesses do futuro a ambição de tirar o maior lucro imediato com o menor trabalho próprio possível, qualquer que seja o prejuizo das gerações futuras." ${ }^{4}$

\section{Documentos de âmbito mundial.}

É apenas no século XX que ações em favor dos bens culturais e naturais vão começar a ter repercussão gerando atitudes efetivas do Estado. Neste século foram realizadas reunião de âmbito internacional que geraram documentos que visavam a proteção mundial de monumentos e bens culturais e naturais. A grande diversidade de documentos lançados em todo o mundo, conhecidos como cartas patrimoniais, serviu em muitos países, mais como um alerta, do que como instrumento eficaz. Mesmo assim, entre essas referências escritas e mundialmente difundidas muitas tiveram desdobramentos e grande repercussão, abrindo a discussão e propondo novas abordagens. Técnicas e teorias dominantes a cada momento da evolução do pensamento preservacionista, muitas vezes levaram à descaracterização de

${ }^{4}$ Citações presentes na obra de Pádua, 2002. 
monumentos de valor histórico, quando da adequação do espaço à vida moderna e era preciso um eixo norteador para evitar a destruição do valor histórico.

Faz parte desse embrião a Carta de Atenas, formulada em outubro de 1931, pois trata de um dos princípios que alterou os rumos da preservação dos bens patrimoniais em todo o mundo e, principalmente, na Europa. Nesse documento, pela primeira vez, foram formuladas normas gerais que todos os países deveriam seguir ao restaurar seus monumentos. Resultado da I Conferência Internacional sobre Restauração, a Carta de Atenas sintetiza os critérios da restauração moderna lançados na Conferência. Nela se afirma, antes de tudo, o princípio do interesse comum das Nações na conservação do patrimônio artístico e arqueológico.

A repercussão da Carta de Atenas foi muito ampla e, com ela ficou estabelecida internacionalmente uma série de princípios, em grande parte ainda vigentes, e que foram a origem de muitas legislações nacionais. O espírito da Carta de Atenas vai estar presente nas leis que vão começar a surgir nos mais diversos países. O sentimento de peservação da história foi tomando conta do todo o mundo e, em muitos países, ocorreram encontros, reuniões e elaboração de decretos visando a defesa dos bens patrimoniais.

As cartas patrimoniais surgem das discussões sobre as normas e condutas que devem ser seguidas na sua preservação e conservação. Porém os primeiros documentos produzidos não explicitavam detalhadamente as intervenções a serem efetuadas. Assim, com o tempo, outras regulamentações e orientações foram sendo editadas, buscando um controle das modernizações que iam sendo introduzidas com as intervenções. As cartas ao longo do tempo, foram sendo complementadas por novas normas e recomendações de procedimentos de preservação. Enumerando as principais cartas, tem-se (Cury, 2000):

Carta de Atenas - Sociedade das Nações, em outubro de 1931 - Conclusões Gerais e Deliberações da Sociedade das Nações do escritório Internacional dos Museus.

Carta de Atenas - Congresso Internacional de Arquitetura Moderna em Atenas, novembro de 1933 (CIAM) - Generalidades, diagnósticos e conclusões sobre os problemas urbanísticos das principais e grandes cidades do mundo.

Recomendação de Nova Delhi - $9^{a}$ Sessão da Conferência Geral das Nações Unidas, ocorrida em 05 de novembro de 1956.

Recomendação de Paris - $12^{\mathrm{a}}$ Sessão da conferência Geral das Nações Unidas, em 19 de novembro a 12 de dezembro de 1962.

Carta de Veneza - II Congresso Internacional de Arquitetos e Técnicos de Monumentos Históricos, em maio de 1964.

Recomendação de Paris 1964 - 13 ${ }^{\text {a }}$ Sessão da Conferência Geral das Nações Unidas, em 19 de novembro de 1964.

Normas de Quito - Reunião sobre Conservação e Utilização de monumentos e Lugares de interesse Histórico e Artístico em novembro/dezembro de 1967. 
Recomendação de Paris 1968 - $15^{a}$ sessão da Conferência Geral das Nações Unidas, de novembro de 1968.

Carta do Restauro - Carta do Restauro, do Ministério da Instrução Pública do Governo da Itália, de 06 de abril de 1972.

Declaração de Estocolmo - Assembleia Geral das Nações Unidas de 05 a 16 de junho de 1972.

Recomendação Paris 1972 - Convenção sobre a Proteção do Patrimônio Mundial, Cultural e Natural de 16 de novembro de 1972.

Resolução de São Domingos - I Seminário Interamericano sobre Experiências na Conservação e Restauração do Patrimônio Monumental dos Períodos Colonial e Republicano, pela OEA, de dezembro de 1974.

Declaração de Amsterdã - Congresso do Patrimônio Arquitetônico Europeu, de outubro de 1975.

Manifesto de Amsterdã - Carta Europeia do Patrimônio Arquitetônico - Ano do Patrimônio Europeu, outubro de 1975.

Carta do Turismo Cultural - Seminário Internacional de Turismo em 8 e 9 de novembro de 1976.

Recomendações de Nairóbi - 19a Sessão da UNESCO ocorrida em novembro de 1976.

Carta de Machu Picchu - Encontro Internacional de Arquitetos ocorrido em dezembro de 1977.

Carta de Burra - Conselho Internacional de Monumentos e Sítios, realizado na Austrália, em 1980.

Carta de Florença - Conselho Internacional de Monumentos e Sítios, em maio de 1981.

Declaração de Nairóbi - Assembleia Mundial dos Estados de 10 a 18 de maio de 1982, no Quênia.

Declaração Tlaxcala - 3 Colóquio Interamericano sobre a Conservação do Patrimônio Monumental de outubro de 1982.

Declaração do México - Conferência Mundial sobre as Políticas Culturais, de 1982.

Carta de Washington 1987 - Carta Internacional para a Salvaguarda das Cidades Históricas de 1997.

Recomendação Paris 1989 - 25a Sessão da Conferência Geral da UNESCO Recomendação sobre a Salvaguarda da Cultura Tradicional e Popular de 15 de novembro de 1989.

Carta de Lausanne - Carta para Gestão e Proteção de Patrimônio Arqueológico, de 1990. 
Carta do Rio - Conferência Geral das Nações Unidas sobre o Meio Ambiente e o Desenvolvimento de 13 a 14 de junho de 1992.

Recomendações de Siri Lanka - Diretivas sobre a Educação e Formação para a Conservação dos monumentos, conjuntos e sítios, de 1993.

Conferência de Nara - Conferência sobre a autenticidade em relação à Convenção do Patrimônio Mundial, de 06 de novembro de 1994.

Carta de Brasília 1995 - Documento Regional do Cone Sul sobre Autenticidade, em 1995.

Recomendação da Europa de 1995 - Recomendação Europa de 11 de setembro de 1995, sobre a conservação integrada das áreas de paisagens culturais como integrantes das políticas paisagísticas, adotada pelo Comitê de Ministros por ocasião do 543ำ encontro de vice-ministros.

Declaração de Sofia - Declaração de Sofia de 09 de outubro de 1996, Carta Internacional sobre a Proteção e gestão do Patrimônio Cultural Subaquático e Princípios para a Criação de Arquivos Documentais de Monumentos, Conjuntos Arquitetônicos e Sítios Históricos e Artísticos, elaborados durante a XI Assembleia Geral do ICOMOS.

Carta de Mar del Plata - Documento do Mercosul sobre Patrimônio Intangível, de junho de 1997.

Carta Internacional sobre Turismo Cultural - A gestão do turismo nos sítios com patrimônio significativo, promulgada no México em1999. Quando foi ainda instituída a Carta do Patrimônio Vernacular Construído, do México, e os Princípios que devem reger a Conservação das Estruturas Históricas em Madeira.

Cartagenas de Índias - Colômbia - Decisão 460 sobre proteção, recuperação de bens culturais do patrimônio arqueológico, histórico, etnológico, paleontológico e artístico da Comunidade Andina, de 25 de maio de 1999.

Recomendação Paris 2003 - 32a Sessão da Conferência Geral das Nações Unidas, de 17 de outubro de 2003 - Convenção para Salvaguarda do Patrimônio Cultural Imaterial.

Nesta relação pode-se destacar, cronologicamente, que houve uma mudança que vai se firmando ao longo do tempo, como uma postura gradativa de deixar o geral, partindo para as particularidades, como uma tendência à fragmentação. Da Carta de Atenas, de 1931, com suas recomendações gerais sobre a conservação do patrimônio artístico e arqueológico vai-se para a de Veneza, de 1964, que já detalha como restaurar, escavar ou publicar os resultados obtidos.

Em 1972, a Carta de Paris cria o Comitê do Patrimônio Mundial que julgará, decidirá as ações e fixará prioridades na proteção do que for considerado patrimônio mundial. A Carta de Burra, de 1981, detalha e define os conceitos de sítios, preservação, conservação, restauração e reconstrução, cheia de detalhes e minúcias a serem seguidas, enquanto a de Florença de 1981, 
especifica a salvaguarda dos jardins históricos do mundo. Na Carta de Washington, de 1987, ficou definido como se deve proteger e defender as cidades históricas e as áreas urbanas, e quais os métodos e instrumentos a serem utilizados para tal. A Carta de Lausane, por sua vez, estabelece os princípios aplicáveis aos diversos setores relacionados à gestão do patrimônio arqueológico, como inventário, prospecção, escavação, documentação, pesquisa e outros itens, chegando até a definir o perfil do pessoal envolvido com esse trabalho. Perfil que será muito bem detalhado com o documento de referência realizado no Siri Lanka, direcionado aos órgãos que formam pessoas que trabalharão na área, chegando até a definição dos princípios que devem reger a conservação de estruturas históricas em madeira, como aconteceu no México em 1999.

\section{Documentos de âmbito nacional}

No que diz respeito ao Brasil, a partir da década de 1920, alguns intelectuais começaram a se posicionar contra o abandono e a dilapidação dos "tesouros" nacionais, levantando a discussão sobre a responsabilidade do Estado em sua salvaguarda. Das idéias surgiram novas concepções sobre patrimônio e preservação e, em 1934, estabeleceu-se no Brasil a Inspeção dos Monumentos Nacionais, vinculada ao Museu Histórico Nacional, do então Ministério da Educação e Saúde Pública e, em 1936, foi implantado um serviço destinado a proteger os bens patrimoniais do país, o Serviço do Patrimônio Histórico e Artístico Nacional (Sphan).

Em 1937 regulamentou-se, pelo Decreto-Lei № 25, de 30 de novembro, a proteção de bens culturais no Brasil $^{5}$. Nesse decreto veem explicitados os valores que justificam a proteção pelo estado de "bens móveis e imóveis" e definida a questão da propriedade desses bens, sendo instituído o Tombamento no Brasil como um instrumento básico de proteção dos nossos bens culturais $^{6}$.

Tombamento e Livro de Tombo são oriundos do Direito Português, onde a palavra "tombar" significa inventariar, arrolar ou inscrever nos arquivos do Reino, os quais eram guardados na Torre do Tombo. De acordo com a Legislação Brasileira tombar significa registrar, com o objetivo de proteger, controlar, guardar. O tombamento de bens culturais é de interesse do estado e da sociedade, pois visa a preservação e a restauração desses bens. Com esse instrumento o Estado passa a intervir diretamente sobre bens públicos ou de particulares em razão da supremacia do interesse público, por conter, esses bens, inestimável valor histórico e cultural. Dessa forma os bens culturais, de grande valor para a sociedade, passaram a integrar o patrimônio histórico da nação merecendo, consequentemente, a proteção do Estado.

Em relação ao tombamento, é preciso ter em mente o conceito de "patrimônio histórico e artístico nacional". No próprio Decreto que instituiu o tombamento está definido esse patrimônio como: "o conjunto de bens móveis e imóveis existentes no país cuja conservação

\footnotetext{
${ }^{5}$ CURY, I. (org). 2000.

${ }^{6}$ Deve-se ressaltar que a proteção dos bens patrimoniais brasileiros já havia sido levantada na Constituição de 1934 , que diz no seu artigo 10 Compete concorrentemente à União e aos Estados: III. Proteger as belezas naturais e os monumentos de valor histórico ou artístico, podendo impedir a evasão de obras de arte (...).
} 
seja de interesse público, quer por sua vinculação a fatos memoráveis da história do Brasil, quer por seu excepcional valor arqueológico ou etnográfico, bibliográfico ou artístico" (Cury, I. (org). 2000), ou seja, são os bens que formam a identidade da nação e que, por isso mesmo ficam protegidos. Assim a declaração de tombamento pode cair sobre qualquer tipo de bem móveis ou imóveis ou locais históricos ou paisagísticos.

O tombamento pode ser feito pela União por meio do Instituto do Patrimônio Histórico e Artístico Nacional (Iphan), em suas diversas regionais, pelos governos estaduais através dos seus órgãos competentes. Em Pernambuco, o tombamento se dá por intermédio da Fundação do Patrimônio Histórico e Artístico de Pernambuco - FUNDARPE ou pelas administrações municipais, utilizando leis específicas ou a legislação federal (Recife tem Zonas Especiais de Preservação).

Cabe também ao cidadão solicitar o tombamento de algo que julgue do interesse geral. É possível a qualquer indivíduo pedir um Tombamento. Qualquer pessoa física ou jurídica, proprietária ou não, pode solicitar a preservação de bens culturais, cuja preservação seja do interesse público, pois o primeiro dos fundamentos para tombar é a supremacia do interesse público sobre o particular, especificamente a adequação do domínio particular às necessidades de interesse público.

O tombamento preserva, no sentido de impedir legalmente a destruição do bem, porém não é a única forma de proteção cultural. Nas ocasiões em que o Poder Público não estiver agindo em seu dever de proteger o patrimônio histórico, artístico e científico do país, a coletividade tem o direito de acioná-lo para diligenciar essa proteção.

Um dos instrumentos que o cidadão pode utilizar para tal é o direito de petição, em via administrativa. Esse direito possibilita a qualquer pessoa de requerer ao Poder Público competente a providência pretendida pela lei e estabelecida como dever de agir. Outro meio de proteção, agora em via judicial, é a ação popular que pode ser utilizada para anular atos lesivos ao patrimônio público, sendo um direito exclusivo do cidadão.

\section{Nossa formação histórica e a ausência de consciência patrimonial}

É notório que, historicamente, existiu certa ausência de responsabilidade da população na preservação das raízes culturais brasileiras. Como país colonizado, formou-se uma consciência patrimonial de forma deturpada e sem o apego característico de um povo que se orgulha de si, de sua história. Mas qual a origem dessa mentalidade e qual a tendência atual?

Historicamente pode-se dizer que o Brasil é um país que ainda não absorveu como parte de suas conviç̧ões, a importância que tem o patrimônio cultural, como acontece na maioria dos países desenvolvidos. Para o brasileiro, assim como para os primeiros colonizadores, a noção de Patrimônio, importante em seu valor cultural, estava na Europa. Os primeiros colonos vieram para o Brasil, mas a sua cultura e o seu patrimônio não se desvinculavam do seu berço europeu. Se hoje se tem povos na Europa que sabem da importância e buscam sempre preservar seus bens culturais é porque esses povos sempre olharam para si, entendendo sua 
própria importância histórica e cultural. O Brasil, diferentemente, foi-se formando com os olhos fora de si, voltados para onde estavam os considerados "verdadeiros" patrimônios a serem reverenciados e protegidos segundo os cânones tradicionais, com os olhos na Europa, gerando-se um sentimento de alienação como se a sua própria cultura não fosse relevante ou digna de atenção.

Para o brasileiro a noção de patrimônio cultural tem sido um valor que foi importado, e não faz parte de seu contexto de vida, não é vivenciado no seu dia-a-dia. Para o brasileiro o reconhecimento da importância do patrimônio e da necessidade de protegê-lo, ocorre por meio de organismos internacionais que "aconselham" a incorporação dessa atitude a todos os países modernos.

Esse reconhecimento é "imposto" através das cartas normativas escritas por esses órgãos internacionais, e a legislação brasileira de certa maneira tem acatado essas decisões internacionais incorporando-as às leis promulgadas, mas ainda como algo que vem de fora, importado e colocado na lista de atividades que deve desenvolver como país moderno, sem que na verdade tenha havido uma incorporação da ideia do valor real das manifestações culturais.

Como no passado, chegaram os europeus representando uma realidade diferente, com um conceito de patrimônio econômico que foi a bandeira da administração colonial, no século XX, também vêm de fora as normas para proteger tanto as expressões materiais como as imateriais, da cultura brasileira, de maneira totalmente desvinculada da realidade (consciência) nacional.

É comum se assistir, na maioria dos países, os grupos dominantes usarem seu poder para promover seu patrimônio, minimizando ou mesmo negando a importância de grupos subordinados, procurando forjar uma identidade nacional à sua própria imagem. No contexto brasileiro a classe dominante não enxerga a importância da proteção cultural, no sentido amplo da manifestação cultural do país, sentida como se fosse um empecilho ao seu próprio interesse e não relacionada à sua realidade. Muito das manifestações culturais brasileiras são desconsideradas e factíveis de serem desapropriadas e excluídas de uma efetiva proteção legislativa.

No Brasil, essa atitude foi resultado de uma sociedade, cujo mundo do trabalho se baseava na escravidão. Nessa sociedade houve sempre dois grupos distintos, os poderosos cuja memória e monumentos são dignos de reverência e preservação, e os vestígios "desvalorizados" dos subalternos, considerados por muitos com desdém e desprezo. O pouco do patrimônio preservado e absorvido como "nacional", reveste-se então de certa inacessibilidade. Apenas alguns podem vivenciá-lo e dele desfrutar. Fica excluída assim a possibilidade de participação de segmentos da população brasileira, como aconteceu e ainda acontece com os índios, por exemplo.

O Brasil que o europeu encontrou era um país riquíssimo em populações ancestrais que deixaram suas marcas e a memória de sua existência. As populações indígenas que os europeus encontraram no Brasil tinham como experiência de vida milhares de anos de 
adaptação no continente. Isso os tinha levado à acumulação de conhecimentos e técnicas de sobrevivência que formavam a base cultural daquelas sociedades.

Na sua forma de viver os índios aprimoraram as técnicas de aproveitamento dos recursos naturais, mantendo sua qualidade de vida e, o que é mais importante, preservando seu potencial e sobrevivência. Além da manutenção de uma qualidade de vida gerando a sobrevivência física os índios se preocupavam em formular mitos, construindo explicações sobre suas origens, vida e morte (Pessis, 2003). Aqui não se teve como herança construções monumentais, mas suas concepções de vida e visões de mundo.

Índios da floresta Amazônica, por exemplo, possuíam, e até hoje possuem, um patrimônio cultural que, além do seu incrível substrato material, chamam atenção pela carga simbólica que apresenta. Darrel Posey, etnobiólogo que estudou os índios Kayapó, no Brasil, mostrou-se estarrecido com a capacidade desses índios no uso de recursos sustentáveis nos trópicos, e ele disse: "se o conhecimento do índio for levado a sério pela ciência moderna e incorporado aos programas de pesquisa e desenvolvimento, os índios serão valorizados pelo que são: povos engenhosos, inteligentes e práticos que sobrevivem com sucesso por milhares de anos na Amazônia." (Posey, 1999: 1-19).

Sobre a cultura material indígena têm-se os relatos do cronista frei dominicano Gaspar de Carvajal que, no século XVI, entrou em contato com índios do Amazonas e ficou fascinado com a cultura material desses povos, mesmo considerando-os bárbaros. Dos artefatos e dos mantos coloridos do povo Omagua, do alto Solimões, e da cerâmica Tapajós, ele disse que era "coisa maravilhosa de se ver (...) tanto de escultura como desenhos e pinturas de todas as cores, dos mais vivos tons" (Carvajal, 1555: 77). De uma das aldeias Omagua que visitou, Carvajal relata: "Encontramos muita louça dos mais variados feitios: havia talhas e cântaros enormes, de mais de vinte e cinco arrobas, e outras vasilhas pequenas, como pratos, escudelas e candieiros, tudo da melhor louça que já se viu no mundo, porque a ela nem a de Málaga se iguala. É toda vidrada e esmaltada de todas as cores, tão vivas que espantam, apresentando, além disso, desenhos e figuras tão harmoniosos, que naturalmente eles (os índios) trabalham e desenham como o romano". Impressionado pela força, autenticidade e qualidade estética desses objetos, Carvajal termina por afirmar que eles eram dignos de figurar nos melhores museus da Europa.

Apesar de reconhecer como sofisticadas e refinadas as obras desse povo, Carvajal classifica-os na ordem de selvagens e bárbaros e, a sua sociedade, de atrasada, partindo do pressuposto de que a obra pudesse ser concebida de forma isolada, independente do seu realizador e do conjunto de valores e tradições culturais que a mantêm. Dessa forma ele inaugura a maneira preconceituosa de olhar a arte indígena, atitude que permanece até hoje em muitos setores da sociedade e que resultou numa discriminação ao índio, levando-os a considerar, tudo que Ihe seja peculiar, como estigmas de inferioridade (Ribeiro, D. 1962: 285). 
De uma maneira geral, os índios do Brasil, nômades em sua forma de vida, tinham seus marcadores de memória representados pelos seus objetos mobiliários ${ }^{7}$. As artes mobiliárias, próprias dos povos nômades, têm uma função de marcador de memória, ou seja, em torno de cada um desses objetos existe uma "história" a ser contada e passada às novas gerações. Esses objetos e, principalmente, as suas "histórias" que são repassadas aos filhos, se integram à cultura imaterial desses povos, mostrando um valor simbólico que ultrapassa o do simples objeto material.

Objetos simbólicos que têm um substrato material móvel são próprios de povos não sedentários. Eles estão presentes, mais fortemente onde não existem paredes. 0 índio brasileiro jamais foi sedentário, sua vida caracterizava-se pela constante mobilidade e a essência de sua cultura não se prendia ao solo, mas às suas mentes. Ainda hoje é assim que mantêm viva sua cultura, através de seus símbolos, suas crenças, seu gestual, que vão além do material, que apenas servem de apoio, de substrato a essas crenças. $O$ valor dos seus objetos rituais, ou seja, patrimoniais, não é econômico, mas simbólico. A imaterialidade de sua cultura esteve e está presente em todos os momentos de sua vida. Mesmo hoje, vivendo em reservas, num sedentarismo obrigatório, com absorção dos valores econômicos da sociedade atual, recorrem, para manter a sua identidade a essa imaterialidade, a esse simbolismo que os mantêm para sempre índios.

Nessa história de formação patrimonial, existe outro ator envolvido: os negros vindos do continente africano e pertencentes a grupos culturais diversificados foram aprisionados e submetidos a uma escravidão degradante e violenta. Foram separados de suas famílias para que, isolados dos seus iguais, enfraquecessem espiritualmente e, em consequência, culturalmente.

Não interessava manter a identidade cultural desse povo. Assim, esperava-se destruí-los como indivíduos, aculturados e sem perspectivas de mudanças. No entanto, essa destruição não foi tão intensa como se pensou. Unidos nas senzalas, os negros reformularam seus ritos para externar suas crenças e mantiveram sua cultura imaterial que, para não despertar a ira dos senhores, quase sempre se escondia por trás dos símbolos dominantes.

Eram grandes as diferenças culturais entre os grupos africanos que vieram para o Brasil, mas o sofrimento e a degradação pelas quais passaram os levaram a uma união entre eles, o que fez surgir uma nova identidade: a de escravo (Ramos, 2006).

Os escravos, durante os séculos de vida no Brasil, foram adquirindo uma nova condição que Ihes possibilitou utilizar o modelo da cultura material das populações dominantes para externar a sua cultura aos moldes cristãos. ${ }^{8}$ O que mudou, evidentemente, foi a maneira pela qual suas identidades puderam se enunciar e se afirmar, fazendo uso inclusive dos próprios meios destinados a aniquilá-las. Pois, na verdade, mesmo utilizando-se dessas formas

\footnotetext{
${ }^{7}$ As pinturas rupestres, apesar de fazerem parte dessa memória, representam as crenças cosmogônicas, são símbolos que não precisam ser levados com o grupo em seus deslocamentos.

${ }^{8}$ Como quando "veneravam" os santos católicos, ou quando mandavam erguer suas igrejas - um exemplo é a do Rosário dos Pretos, no Recife.
} 
patrimoniais dos dominantes, por trás de tudo aquilo estava suas crenças, seus símbolos, sua cultura imaterial.

Os bens móveis tiveram um significado simbólico importante na preservação da cultura negra. São objetos que têm valor pelo que significam, são símbolos que falam de aptidões específicas, de habilidades especiais, que individualizam as pessoas.

Desse encontro entre culturas, o Brasil, que recebeu na sua trajetória histórica outros grupos culturalmente diversos, assistiu, ao longo dos séculos, o lento apagar de uma forte diversidade cultural, acarretado pelo genocídio indígena, pela dominação cultural de seus escravos e pela mestiçagem que, apesar de advir dos diversos povos que formaram as bases da nação, não se reconhece na sua própria cultura, nem histórica, nem pré-histórica.

A chegada do europeu ao Brasil gerou o encontro de povos com prioridades totalmente diferentes, com valores antagônicos, o que levou à criação de um mundo novo de genocídio, escravidão e dominação europeia, formando uma nação mestiça marcada pela sua história de 5 séculos.

Em uma relação de dependência e subordinação, o brasileiro teve sua identidade formada ao longo desse período, criando uma mentalidade cujo referencial cultural está na base infundida pelo colonizador, com a noção do provisório, da exploração, do lucro fácil e da não necessidade de preservar. Assim a nação se constituiu apagando diferenças étnicas e culturais importantes, e todos os brasileiros têm aceitado, por todo esse tempo, os discursos que eliminavam identidades anteriores, e pouco ou quase nenhum esforço foi desprendido para mudar esses discursos.

Os europeus que ocuparam o Brasil, após 1500, em sua postura de colonizador, vieram no objetivo imediato de obter lucros financeiros explorando os bens naturais da terra. Toda a estrutura montada na colônia visava à manutenção dessa máquina exploratória que era a administração colonial. Eles estavam prontos para destruir física e ideologicamente todos os que tentassem impedir a sua realização.

A ideia de depredação patrimonial é, pois, um fenômeno colonial, faz parte da lógica de exploração mercantilista. As preocupações registradas na historiografia, com a depredação dos recursos, ainda em princípios da colonização, visavam primordialmente à manutenção da exploração das riquezas que o ambiente fornecia. $O$ valor financeiro do patrimônio movia o mercado. O papel do pau-brasil no mundo da moda, das finanças e da indústria têxtil europeia, o açúcar, dinheiro vivo nas negociações, movimentaram fortunas e interesses no mundo inteiro.

Por todos os séculos seguintes, a ideologia do lucro, em relação aos bens patrimoniais do país, direcionou a ação do colono em relação a eles. A pressão crescente sobre os recursos naturais gerou uma irreparável degradação ambiental. 
Na natureza retirou o pau-brasil até esgotá-lo, cortou árvores sem controle para retirada de madeiras até quase extinguir a, antes exuberante, Mata Atlântica. É a política da pura extração, sem a preocupação de replantio. Os animais foram caçados até sua quase extinção. ${ }^{9}$ Os rios foram poluídos até à sua quase morte. Os modelos adotados, de exploração como forma de domínio da natureza, levaram à agressão, sem reservas, do meio ambiente. Acreditava-se em donos da terra e sentia a necessidade de dominá-la. Os recursos naturais foram tratados como simples mercadorias a serem exploradas (Ramos, 2006).

Na última década do século XX pesquisas mostravam que, em torno de $150 \mathrm{mil} \mathrm{km}^{2}$ de floresta tropical, são derrubados por ano em todo o mundo, sendo que, no Brasil, são em torno de 20 mil km² de floresta amazônica. Além desta, a mata Atlântica é a mais ameaçada no Brasil e a quinta no mundo, já tendo sido devastados $97 \%$ de sua área total (Victor, C. A, 2002: 100). A chuva ácida decorrente das emissões de enxofre advindas das indústrias e centrais elétricos poluentes acentuou o problema levando muitas árvores à morte ${ }^{10}$.

Os trabalhos realizados demonstraram ainda que as reservas de recursos de água estavam se esgotando em ritmo assustador, enquanto aumenta em muito o seu consumo. Falou-se então da necessidade urgente de uma postura de preservação dos recursos naturais existentes e de sua ampliação através de princípios voltados à conservação, onde a permanência das áreas florestais naturais e a imediata reposição das que foram destruídas pelo corte e pelo fogo, assim como a conservação dos rios e riachos são essenciais. ${ }^{11} \mathrm{~A}$ pesquisa também mostrou que grande área do mundo ficará sem água em 30 anos. Regiões dos Estados Unidos, Europa Ocidental e Oriental, e parte do Planalto do México; a área central da região oeste da Argentina e do nordeste do Brasil corre o perigo da escassez total.

As atitudes de desapego que se tem até hoje, são reflexos de uma memória de depredação que se sobrepõe a uma tênue memória de conservação, ao mesmo tempo em que é parte de um modo de agir cultural que deve ser substituído por uma maior consciência dos cidadãos, uma compreensão das diferenças existentes entre os indivíduos e as sociedades atuais, através das diferentes relações que cada sociedade estabelece no decorrer de sua história.

Em boa parte dos segmentos sociais do país, a questão cultural ainda aparece como algo supérfluo no âmbito de suas necessidades - não faz parte das imposições básicas da vida, pelas quais se luta para obtê-las. Existe uma ausência de consciência patrimonial no Brasil.

A maioria dos brasileiros não se percebe como construtor do seu meio ambiente histórico, do seu patrimônio cultural, e não os inclui como parte de sua vida vendo-os, apenas através de sua rentabilidade econômica. Por fim, pode-se dizer que a população brasileira vive desvinculada do seu patrimônio cultural, encarado com supérfluo, prescindível, um luxo inútil face aos prazeres da depredação.

\footnotetext{
${ }^{9}$ De acordo com o IBGE há pelo menos 330 espécies e subespécies da fauna brasileira ameaçadas de extinção, sendo 34 espécies de insetos, 22 de répteis, 148 de aves e 84 de mamíferos.

${ }^{10} \mathrm{~A}$ chuva ácida mistura-se aos húmus no solo dos boques levando as árvores à morte. Os íons de hidrogênio formados retiram elementos vitais do solo, o que vem acarretando a morte de árvores em florestas dos EUA e da Europa.

${ }^{11}$ O Brasil Rumo ao Primeiro Mundo. Agricultura e Alimentos, site Egon Nort.
} 
O conceito de patrimônio, trazido pelos órgãos internacionais e incorporado às leis brasileiras como aquilo que pertence a todos, não é entendido como tal, mas como algo limitador de poderes e causador de prejuízos aos que detêm a posse econômica do bem. É sempre a memória da depredação sobrepondo-se à memória da conservação.

No espaço construído também ficam as marcas dessa ideologia - a da tradição do aumento desenfreado de produção, de destruição construtiva e de modernização - argumento também usado em muitos outros ecossistemas urbanos do mundo, a partir do qual são demolidos muitos dos espaços e edifícios históricos, descaracterizando os traçados das cidades, gerando graves problemas ambientais.

Esse efeito devastador vem desde o primeiro contato com o mundo moderno. Os colonizadores quando se estabeleceram no Brasil destruíram inúmeras tabas indígenas, matando, perseguindo e escravizando milhares de índios. De muitas aldeias indígenas só se tomou conhecimento através dos relatos dos viajantes dos séculos XVI e XVII.

Além da destruição física de elementos da cultura das minorias e subordinados por toda nossa história, os donos do poder sempre tiveram um maior acesso às realizações materiais de seu pensamento, o nosso patrimônio construído reflete bem esse maior acesso. Às minorias só foram permitidas as expressões não monumentais e não muito duráveis do patrimônio edificado. O patrimônio cultural no Brasil é fruto das forças que os detentores do poder aplicaram na nossa formação durante 500 anos de história, ou seja, a herança patrimonial é hoje, fruto da influência que esses formadores da estrutura social, exerceram sobre a sociedade.

Fundado na mestiçagem, o Brasil apresenta hoje uma rica diversidade cultural que deve ser mais claramente conhecida e respeitada. O Brasil é o produto de uma mistura de culturas. A produção humana dessa massa diversificada, representada pelos seus elementos históricos e estéticos mais significativos, deve ser vista como acervo da Nação e deve ser resguardada e protegida. O brasileiro precisa se reconhecer na sua pré-história e história - identificando raízes de alguns de seus comportamentos - criar estratégias para retirar do inconsciente coletivo essa ideologia do provisório, da destruição, da exploração, da sobrepujança do econômico sobre o cultural. Enquanto o brasileiro quantificar o seu acervo cultural monetariamente, os interesses particulares se sobreporão e esse patrimônio será espoliado. Deve incorporar ao patrimônio cultural e natural, valores outros além do econômico, para que se tornem os agentes dessa mudança e formem as novas gerações que serão os adultos do futuro e promotores de uma nova ideologia, onde o econômico terá sua posição no panorama cultural, como um fator a mais de valorização e não como valor superior e esmagador.

São anos de uma ideologia predatória que deve ser urgentemente mudada. O que restou desse quadro de destruição é decorrente da luta de alguns defensores que se manifestam e bradam em defesa da memória histórica. Aos que conseguiram incutir-se de um pouco de lucidez resta a obrigação de tentar mudar esse quadro, para que o patrimônio cultural brasileiro possa ser salvo. Existe uma dicotomia em relação à proteção patrimonial, entre o povo brasileiro, de uma maneira geral, e as lutas de alguns, para efetivá-la. A conservação do patrimônio só ocorrerá efetivamente com a participação de toda a população. 


\section{As corresponsabilidades e a conscientização social}

Infelizmente uma participação efetiva da população na preservação dos bens patrimoniais ainda não é comumente realizada no Brasil. A maior parte de nosso povo não conhece a sua história e, portanto, os valores remanescentes de símbolos não têm, na maioria das vezes, fundamentos reais nem raízes na população.

Para conseguir a participação da sociedade é preciso que reconheça a importância do seu patrimônio, para que ela se veja nele e, assim, possa criar uma perspectiva de conhecimento, de valorização e uma verdadeira apropriação do patrimônio. É necessário então, agir diretamente junto à população para que mude de atitude, identificando e percebendo a importância da preservação dos bens que representam a sua cultura, na sua vida e na da sua comunidade. É sabido que, para que todos sejam reconhecidos como participantes na construção de um país faz-se importante a tomada de posição e que seja levado a sério o conhecimento de cada um desses povos (Possey, 1999).

Quando a população participa, a preservação torna-se efetiva. Os instrumentos de financiamento existem, mas são limitados diante da gama de bens que necessitam de proteção. Para acioná-los é imprescindível a interferência da população elegendo os bens que pretenda proteger.

Não se pode permitir que se distancie ainda mais do respeito, reconhecimento e identificação com o patrimônio cultural, principalmente quando se pratica o caminho inverso descontruindo um processo de apoio legislativo como o que se viu acontecer no Brasil recentemente. A aprovação de medidas que põem abaixo uma série de conquista e avanços são incongruentes e representam os interesses dos descompromissados com a proteção patrimonial do país. Um dos principais instrumentos normativos que disciplinava a execução de projetos de pesquisa arqueológica no âmbito do licenciamento ambiental, a Instrução Normativa do IPHAN n 001 , de 25 de março de 2015, teve sua aplicação sustada pelo Decreto Legislativo ${ }^{\circ}$ 540/2016, fragilizando esse importante mecanismo de proteção ao patrimônio arqueológico que vinha contribuindo na ampliação da obrigatoriedade da análise do impacto sobre o patrimônio dos grandes empreendimentos realizados no país. Esse decreto alimenta a velha e constante ideia de depredação patrimonial, um fenômeno colonial, parte da lógica de exploração mercantilista.

Nesse contexto de retrocesso, a Educação Patrimonial torna-se imprescindível. A Carta de Atenas de 1931 já mostra a importância da educação patrimonial na defesa do patrimônio cultural. No seu capítulo VII, item b, tem-se:

\section{O papel da educação e o respeito aos monumentos:}

A conferência, profundamente convencida de que a melhor garantia de conservação de monumentos e obras de arte vem do respeito e do interesse dos próprios povos, considerando que esses sentimentos podem ser grandemente favorecidos por uma ação apropriada dos poderes públicos, 
emite o voto de que os educadores habituem a infância e a juventude a se absterem de danificar os monumentos, quaisquer que eles sejam, e Ihes façam aumentar o interesse, de uma maneira geral, pela proteção dos testemunhos de toda a civilização.

A negação ou não aplicabilidade das leis patrimoniais leva a um triste retrocesso. O não conhecimento ou a não identificação com conceitos como os de patrimônio histórico e cultural, orgulho e respeito pela história do país, levam à realização de atos que prejudicam sensivelmente a conservação e preservação das expressões culturais. São agressões que se tornam ainda mais estarrecedoras, quando partem de políticos que detêm o poder de modificar as leis em suas mãos e que foram eleitos para defender o povo e a nação.

Fica cada vez mais claro que, para se por em prática uma política de intervenção que seja ampla e democraticamente abrangente, deve-se adotar a educação patrimonial como ponto de partida para alcançar uma mudança de mentalidade do povo brasileiro como um todo. A valorização histórica dos bens artísticos e culturais e o respeito pelos ambientes naturais é algo que deve ser incutido em todos os grupos sociais do país. O conhecimento e a preservação do acervo cultural que marca a identidade de um grupo deve ser cuidadosamente cultivado, pois a descaracterização identitária, como reflexo de perdas do acervo histórico e cultural, quando toma grandes proporções torna-se irreversível.

\section{Referências}

ANDRADE, A. L. D. O tombamento na preservação de áreas naturais, In: Revista do Patrimônio Histórico e Artístico Nacional n.19, 1984, p 41-44.

ALVAREZ, J. L. Sociedad, Estado y Patrimonio Cultural. Madrid: Espasa Calpe, 1992.

ABREU, R.; CHAGAS, M. (orgs). Memória e Patrimônio, ensaios contemporâneos, Rio de Janeiro: DP\& A, 2003.

ALMEIDA, F. D. M. Competências na Constituição de 1988. São Paulo: Editora Atlas S.A., 1991.

ASSINI, N. e FRANCALACCI, P. (Coord.). Manuale dei Beni Culturali. Pádua: Cedam, 2000.

BALLART, J. El Patrimonio Histórico y Arqueológico: Valor y Uso. Barcelona: Ariel, 1997.

BOTELHO, I. Dimensões da cultura e políticas públicas, In: Revista do Instituto Polis. São Paulo: Perspectiva, v. 15, n.2, 2001.

CARVAJAL, F. G. (1542) Descobrimentos do Rio das Amazonas. Rio de Janeiro: Companhia Editora Nacional, 1941.

CHOAY, F. A Alegoria do Patrimônio, tradução Luciano Vieira Machado. São Paulo: Ed. UNESP, 2001.

COSTA, J. P. O. Patrimônio Natural e estatuto de Tombamento, In: Revista do Patrimônio Histórico e Artístico Nacional n.21, 1986, p 21-24.

CURY, I. (org). Cartas patrimoniais. Iphan, 2a .ed., Rio de Janeiro, 2000. 
FONSECA, M. C. L. O Patrimônio em Processo - trajetória da política federal de preservação no Brasil. 2a.ed. Rio de Janeiro: Editora UFRJ / Minc / Iphan. . 2005

DIAS, João José Alves. "Introdução" in Ordenações Manuelinas: livro I a V : reprodução em fac-símile da edição de Valentim Fernandes (Lisboa, 1512-1513). Lisboa: Centro de Estudos Históricos da Universidade Nova de Lisboa, 2002

MAGALHÃES, A. Bens Culturais: Instrumento para um desenvolvimento harmonioso. In: Revista do Patrimônio Histórico e Artístico Nacional n.20, 1984, p 40-44

MENESES, U.T.B. O patrimônio Cultural entre o público e o privado. In: DPH. O direito à memória: patrimônio histórico e cidadania. São Paulo: DPH/SMC, 1992.

OLIVEIRA, A. S. A codificação do Direito. ano 7, n. 60, 1 nov. Teresina: Jus Navigandi, 2002.

PADUA, J. A. Um Sopro de Destruição. São Paulo: Editora Jorge Zahar, 2002.

PESSIS, A. M. Imagens da Pré-História. Parque Nacional da Serra da Capivara. FUMDHAM/PETROBRÁS. São Paulo: A\&A Comunicação, 2003.

POSEY, D. Culture and nature - The inextricable link. In: Re and spirit values of biodiversity. Londres: UNEP, 1999.

RAMOS, A. C. P. T. Posturas e Práticas de Preservação. O Confronto entre Modelos Participativos e Centralizados na Manutenção dos Bens Culturais em Pernambuco (1978 - 2006). Tese de doutorado. Programa de Pós-graduação em Arqueologia da UFPE, Recife, 2006

RIBEIRO, D. A política indigenista brasileira. Rio de Janeiro: Ministério da Agricultura, SIA,1962.

SECRETARIA DO PATRIMÔNIO HISTÓRICO E ARTÍSTICO NACIONAL. Proteção e revitalização do patrimônio cultural no Brasil: uma trajetória. Brasília: SPHAN, 1980.

INSTITUTO DO PATRIMÔNIO HISTÓRICO E ARTÍSTICO NACIONAL. Disponível: http://www.iphan.gov.br. UNESCO. http://www.unesco.org, (Cartas Patrimoniais), 2000. 